\title{
Testes fitoquímicos em extratos foliares de Oeceoclades maculata Lindl. (Orchidaceae)
}

\begin{abstract}
CARRERA, G.C. '; BENEDITO, E.F.'; SOUZA-LEAL, T.2; PEDROSO-DE-MORAES, C. 3; GASPI, F.O.G³. ${ }^{1}$ Alunos de Iniciação Científica - Bacharelado em Farmácia e Bioquímica - Centro Universitário Hermínio Ometto - UNIARARAS. Av. Maximiliano Baruto, 500. CEP: 13706-900. Araras, SP. Brasil. ${ }^{2}$ Aluno de iniciação científica - Bacharelado e Licenciatura em Ciências Biológicas - Centro Universitário Hermínio Ometto UNIARARAS. Av. Maximiliano Baruto, 500. CEP: 13706-900. Araras, SP. Brasil. ${ }^{3}$ Docentes do Centro Universitário Hermínio Ometto - UNIARARAS. Av. Maximiliano Baruto, 500. CEP: 13706-900. Araras, SP. Brasil. Autor para correspondência: pedroso@uniararas.br
\end{abstract}

RESUMO: O presente trabalho teve por objetivo determinar a capacidade antioxidante de Oeceoclades maculata. A atividade foi determinada de acordo com a capacidade do extrato hidroalcoólico das folhas reduzir o radical DPPH. Os resultados obtidos permitem concluir que os conteúdos de polifenóis e flavonas/flavonóis são maiores no extrato preparado a frio (EBHF) do que no extrato preparado a quente (EBHQ), sugerindo que o aquecimento usado na preparação do extrato altera esses componentes ativos. Portanto, para esta espécie deve ser realizado o método de extração a frio para conservar as substâncias que possuem atividade antioxidante.

Palavras-chaves: Flavonoides, polifenóis, plantas medicinais.

\begin{abstract}
Phytochemical tests in Oeceoclades maculata Lindl. (Orchidaceae) leaf extracts. This work aimed to determine the antioxidant capacity of Oeceoclades maculata. The antioxidant activity was determined in accordance with the ability of the hydroalcoholic extract of the leaves to reduce the DPPH radical. The results showed that the polyphenol and flavonoid contents are greater in the cold extract (EBHF) than in the hot extract (EBHQ), which suggests that the heating effect in the preparation of the extract modifies these active compounds. Therefore, for this species, the cold extraction method must be carried in order to conserve the substances with antioxidant activity.
\end{abstract}

Keywords: Flavonoids, polyphenols, medicinal plants.

\section{INTRODUÇÃO}

Diante do diverso e inesgotável arsenal terapêutico presente nas plantas, as indústrias farmacêuticas investem cada vez mais em pesquisas envolvendo plantas medicinais, uma vez que grande parte dos medicamentos existentes no mercado originou-se de representantes do reino Plantae (Ferreira \& Matsubara, 1997). Tal constatação torna a confirmar a necessidade e a importância da pesquisa para a comprovação das atividades farmacológicas das plantas medicinais utilizadas popularmente ou para a descoberta das suas propriedades curativas e toxicológicas (Gasparri, 2005). Neste sentido, o Brasil, com sua enorme biodiversidade, abriga 55 mil espécies catalogadas e apresenta-se com um grande potencial para a pesquisa e a exploração na área de plantas medicinais (Alves et al., 2000; Gasparri, 2005), podendo contribuir para o desenvolvimento de novos medicamentos produzidos a partir de plantas (Ferreira \& Matsubara, 1997). Nesse ínterim, Orchidaceae representa uma das famílias mais derivadas e biodiversas entre as Angiospermas, indicando potencial de síntese de inúmeros compostos secundários passíveis de serem utilizados como fitoterápicos. Muitas são as espécies de orquídeas que sintetizam compostos de importância fitoterápica, sendo amplamente usadas como plantas medicinais na Índia e na China; contudo, são poucos os estudos em relação à identificação de princípios ativos em representantes nacionais (Pedroso-de-Moraes et al., 2006). 
Oeceoclades maculata (Lindl.) Lindl. é uma espécie de orquídea de hábito terrestrehumícola de porte herbáceo, sempre verde, com crescimento simpodial (Menini-Neto, 2004a), com ampla capacidade de colonização de habitats sendo considerada, até mesmo, como planta invasora (Cohen \& Ackerman, 2009). No Brasil, tal espécie é encontrada em diversas fitofisionomias, tais como: a Mata Estacional Semidecidual (Ivanauskas \& Rodrigues, 2000; Menini-Neto et al., 2004a; 2004b; Kinoshita et al., 2006; Pansarin \& Pansarin, 2007), o Cerrado (Batista \& Bianchetti, 2003; Batista et al., 2005) e a Caatinga (Araújo et al., 2005), ocorrendo na maioria das vezes em matas ribeirinhas destes biomas (Menini-Neto et al., 2004b; Araújo et al., 2005; Bueno et al., 2007). Ainda, Ferreira et al. (2010), em levantamento realizado na região central de São Paulo, catalogaram a espécie em todas as fitofisionomias estudadas.

A triagem de classes de metabólitos especiais maioritários é uma das etapas iniciais da pesquisa química em plantas e possui o objetivo de conhecer os constituintes químicos naturais contidos nas espécies vegetais ou avaliar a sua presença em um determinado material e, a partir disto, orientar a extração e/ou fracionamento de extratos no sentido de grupos de maior interesse farmacológico em pesquisas aplicadas e também no isolamento de moléculas biologicamente ativas (Matos, 1997; Simões, 2004). Quando não se dispõe de estudos químicos sobre a espécie de interesse, a análise preliminar pode indicar os grupos de metabólitos secundários relevantes na mesma. Caso o interesse esteja restrito a uma classe específica de constituintes ou às substâncias responsáveis por certa atividade biológica, a investigação deverá ser direcionada para o isolamento e a elucidação estrutural das mesmas (Simões, 2004). Assim, o presente trabalho apresentou por objetivo obter extratos a frio (EBHF) e a quente $(E B H Q)$ da espécie O. maculata para detecção de classes de metabólitos especiais maioritários presentes nestes extratos e sua possível atividade antioxidante.

\section{MATERIAL E MÉTODOS}

\section{botânico. \\ Obtenção e identificação do material \\ O material botânico utilizado neste trabalho,} 50 folhas de 20 espécimes de Oeceoclades maculata, foi proveniente do Arboredo do Centro Universitário Hermínio Ometto - Uniararas. Para a confirmação do táxon, um indivíduo fértil da espécie, identificado pelo botânico, Prof. Dr. Cristiano
Pedroso de Moraes, foi herborizado segundo os procedimentos usuais (MORI et al., 1989) e uma exsicata foi depositada na coleção do Laboratório de Botânica e Análises Ambientais da instituição (Voucher: 69).

\section{Processamento do material}

Extração a frio: Após a coleta, $100 \mathrm{~g}$ de folhas de $O$. maculata foram selecionadas e limpas. Em seguida, as folhas frescas passaram pelo processo de maceração em $500 \mathrm{~mL}$ de solução hidroalcoólica $70 \%$ por sete dias, à temperatura ambiente. O filtrado resultante foi evaporado sob vácuo a temperatura de $40^{\circ} \mathrm{C}$ até a remoção total do etanol, sendo obtido desta forma $120 \mathrm{~mL}$ do extrato bruto hidroalcoólico a frio (EBHF).

Extração a quente: Uma porção de $100 \mathrm{~g}$ de folhas frescas foi submetida à extração em 100 $\mathrm{mL}$ de solução hidroalcoólica $70 \%$ em aparelho de Soxhlet a temperatura de $70^{\circ} \mathrm{C}$ por 2 horas, sendo obtido desta forma $24 \mathrm{~mL}$ de extrato bruto hidroalcoólico a quente (EBHQ).

Avaliação da atividade antioxidante do extrato de Oeceoclades maculata.

A atividade scavenger do extrato vegetal foi determinada usando difenilpicrilhidrazil (DPPH), um radical livre estável. À medida que o DPPH é reduzido por um antioxidante desaparece a banda de absorção em $517 \mathrm{~nm}$.

As medidas foram feitas adicionando à amostra uma mistura contendo $1 \mathrm{~mL}$ de tampão acetato $100 \mathrm{mM}, \mathrm{pH} 5,5,1 \mathrm{ml}$ de etanol e $0,5 \mathrm{ml}$ de DPPH 500mM. Logo após, a absorbância foi medida em $517 \mathrm{~nm}$ (Bloiss, 1998). A metodologia utilizada para atividade antioxidante foi realizada em triplicata para cada concentração analisada. Os resultados foram posteriormente analisados estatisticamente.

\section{Determinação de polifenóis totais}

Os compostos fenólicos presentes no extrato foram dosados a partir de uma curva padrão de catequina. As amostras do extrato $(100 \mathrm{~mL}$ de uma solução $10 \mathrm{mg} / \mathrm{mL}$ ) foram adicionadas a uma mistura contendo $2 \mathrm{~mL}$ do reagente de FolinCiocalteu e 1,6 mL de $\mathrm{NaCO}_{3} 7,5 \%$. Em seguida, a absorbância foi medida em $765 \mathrm{~nm}$.

\section{Determinação de flavonoides}

A dosagem de flavonoides no extrato foi realizada utilizando-se uma curva padrão de quercetina. A amostra (100 mL de uma solução 10 $\mathrm{mg} / \mathrm{mL}$ ) de extrato vegetal foi misturada com $1 \mathrm{~mL}$ de uma solução contendo piridina:água: $\mathrm{ALCl}_{3} 12 \%$ (17:80:3), com $60 \mathrm{~mL}$ de ácido acético glacial e 1240 $\mathrm{mL}$ de uma mistura de DMSO:água (1:1). Logo após, a absorbância foi medida em 420nm. 
Análise de grupos funcionais (Costa, 1986; Matos, 1997; Simões, 2004)

Teste para agliconas flavônicas: Os extratos foram evaporados e ressuspendidos em $2 \mathrm{~mL}$ de metanol $50 \%$ a quente. A cada um dos extratos assim preparados foram adicionadas limalhas de magnésio e $0,5 \mathrm{~mL}$ de ácido clorídrico concentrado. Após um repouso de 15 minutos foi observado se ocorreria o aparecimento da coloração avermelhada característica.

Teste para taninos: Os extratos foram aquecidos em banho-maria fervente até o volume de $5 \mathrm{~mL}$. Após a adição de três gotas de solução de Cloreto férrico $1 \%$ foi observada a presença ou ausência da coloração azul ou verde característica.

Teste para cumarinas: Com o auxílio de um capilar, foram feitas duas manchas de aproximadamente $1 \mathrm{~cm}$ de diâmetro em um papel de filtro. Em uma das manchas foi aplicada uma gota de solução alcoólica de Hidróxido de potássio $0,5 \mathrm{~N}$. Em seguida, as manchas foram expostas a luz ultravioleta e observada a presença ou ausência de fluorescência azul ou verde.

Teste para alcaloides: Os extratos foram concentrados e solubilizados em $3 \mathrm{~mL}$ de Ácido clorídrico $2 \%$. Logo após, foram divididos em três porções iguais, nas quais foram gotejadas aos poucos os reagente de Mayer, de Dragendorff e a solução de Ácido silicotúngstico, respectivamente. Após agitação foi observado o aparecimento ou a ausência de precipitados.

Teste para triterpenoides e esteroides: Os extratos foram evaporados até a secura, sendo logo após, solubilizados em etanol. Acrescentouse $10 \mathrm{~mL}$ de hidróxido de potássio $0,5 \mathrm{M}$, sendo submetido a refluxo por 1 hora. Após a filtração dos extratos obtidos, foi adicionado $20 \mathrm{~mL}$ de água destilada. Os extratos foram evaporados em rotaevaporador até a total remoção do etanol.
As frações aquosas foram extraídas em funil de separação com éter etílico, sendo que este processo foi repetido três vezes. As frações etéreas foram submetidas à reação de Liebermann-Burchard, que consiste na adição de anidrido acético e Ácido sulfúrico concentrado.

Teste para antocianinas: Os extratos foram evaporados até a secura, sendo logo após solubilizados em etanol. Acrescentaram-se $10 \mathrm{~mL}$ de Ácido clorídrico $20 \%$, sendo submetido a refluxo por 1hora. Após a filtração dos extratos obtidos, foram adicionados $20 \mathrm{~mL}$ de água destilada. Os extratos foram evaporados em rotaevaporador até a total remoção do etanol. As frações aquosas foram extraídas em funil de separação com éter etílico, sendo que este processo foi repetido três vezes. A fração aquosa ácida foi alcalinizada até $\mathrm{pH}$ 9-10, sendo observada a presença ou ausência de mudança de coloração característica.

Teste para saponinas: Os extratos hidroalcoólicos foram agitados por três minutos e foi observada a presença ou ausência de espuma persistente e abundante.

Os resultados obtidos nos testes realizados na triagem fitoquímica foram estabelecidos conforme os seguintes parâmetros.

$$
\begin{aligned}
& \text { Fortemente Positivo }=(+++) \\
& \text { Moderadamente Positivo }=(++) \\
& \text { Positivo }=(+) \\
& \text { Negativo }=(-)
\end{aligned}
$$

\section{RESULTADOS}

Os processos extrativos a frio e a quente resultaram em extratos de coloração verde intenso. Foram observados resultados fortemente positivos $(+++)$ para Agliconas flavônicas e Taninos no EBHF e para o EBHQ estas substâncias foram detectadas,

TABELA 1. Resultados obtidos na triagem de grupos funcionais dos extratos obtidos a frio (EBHF) e a quente (EBHQ) das folhas de Oeceoclades maculata Lindl.

\begin{tabular}{ccc}
\hline TESTES REALIZADOS & EBHF & EBHQ \\
\hline Agliconasflavônicas & +++ & + \\
Taninos & +++ & + \\
Cumarinas & - & - \\
Alcaloides & - & - \\
Triterpenoides e Esteroides & - & - \\
Antocianinas & - & - \\
Saponinas & - & - \\
\hline
\end{tabular}

Fortemente Positivo $=(+++)$, Moderadamente Positivo $=(++)$, Positivo $=(+)$, Negativo $=(-)$. 
porém com resultado positivo (+). Os resultados foram negativos (-) para Triterpenoides, Esteroides, Antocianinas, Cumarinas, Alcaloides e Saponinas para ambos os extratos (Tabela 1).

Avaliação da atividade antioxidante dos extratos de Oeceoclades maculata.

A atividade antioxidante foi determinada de acordo com a capacidade dos extratos obtidos a frio (EBHF) e a quente (EBHQ) reduzirem o radical cromógeno DPPH. Foi observado que $100 \mu \mathrm{L}$ de ambos os extratos apresentaram a capacidade de sequestrar tal radical, portanto, apresentam atividade antioxidante. Entretanto, tal capacidade ocorre de maneira mais efetiva no EBHF quando comparado ao EBHQ. O EBHF apresenta atividade antioxidante dose-dependente, sendo significativa a partir de $50 \mu \mathrm{L}$ (Figura 1).

\section{polifenóis totais.}

Determinação de flavonoides e de

O conteúdo de flavonoides nos extratos preparados a frio e a quente foi expresso como equivalentes de quercetina. O conteúdo de polifenóis totais nos extratos preparados a frio e a quente foram expressos como equivalentes de catequina (Tabela 2). A quercetina e a catequina foram usadas para preparar as curvas de calibração.

Os resultados obtidos nas determinações de flavonoides e de polifenóis totais mostram que, na mesma concentração, o extrato EBHF apresentou maior atividade do que o extrato EBHQ (Tabela 2), possivelmente isto ocorreu devido a alterações químicas com o aquecimento dos componentes químicos que participam de tal atividade. Neste caso, nota-se uma perda de $61,56 \%$ dos polifenóis totais e de $64,51 \%$ de flavonoides na extração a quente.

\section{DISCUSSÃO}

São extremamente escassas na literatura as informações sobre a utilização de orquídeas Americanas e, principalmente nacionais, como plantas medicinais, sendo amplamente conhecida somente a utilização de representantes do gênero Vanilla, com maior destaque à Vanilla planifolia Jacks. ex Andrews, V. pompona Schiede e V. tahitensis J.W. Moore, espécies hemiepífitas, de onde é extraída a vanilina (Pedroso-de-Moraes \& Fontana, 2005; Pedroso-de-Moraes et al., 2012), de Cyrtopodium paranaense Schltr., espécie terrestre, e de Oncidium flexuossum Sims., de hábito epífito. Estas duas últimas espécies apresentam, devido, provavelmente, à quantidade de flavonoides detectados, ampla ação anti-inflamatória e cicatrizante, respectivamente (Boscolo \& Valle, 2008; Carniello et al., 2010; Gaspi et al., 2011). Mesmo assim, diante de tais informações à cerca da utilização de espécies medicinais de Orchidaceae, comparados à Índia e China, nosso conhecimento é ainda incipiente (Pedroso-de-Moraes et al., 2006; Bulpitt et al., 2007; Singh \& Duggal, 2009). Entretanto, um fato curioso é o de que espécies de Orchidaceae dos Neotrópicos, geralmente são quimicamente caracterizadas por apresentar maiores quantidades
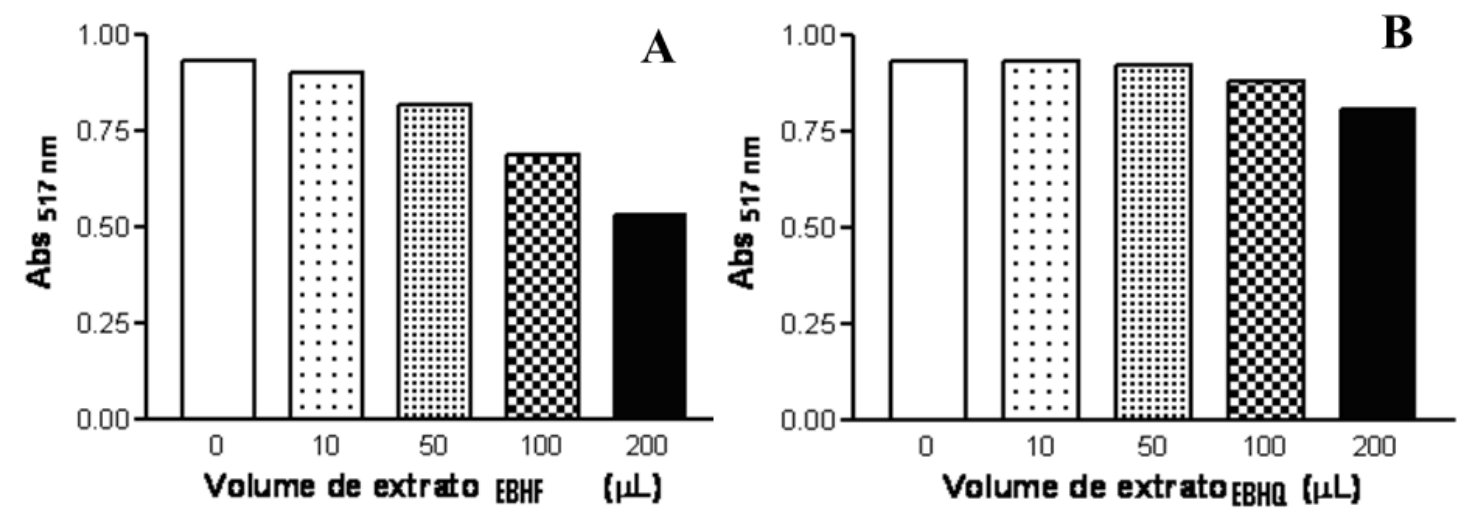

FIGURA 1. Redução do radical DPPH por diferentes volumes de extrato de Oeceoclades maculata a frio (EBHF) $(A)$ e a quente $(E B H Q)(B)$. ANOVA $\left({ }^{*} p<0,05\right)$.

TABELA 2. Conteúdo de flavonoides e polifenóis totais nos extratos preparados a frio (EBHF) e a quente (EBHQ).

\begin{tabular}{lll}
\hline Fitoquímicos & Extrato EBHF $(\mu \mathrm{g} / \mathrm{mL})$ & Extrato $\mathrm{EBHQ}(\mu \mathrm{g} / \mathrm{mL})$ \\
\hline Polifenóis totais & 110,00 & 42,28 \\
Flavonoides & 10,34 & 3,67 \\
\hline
\end{tabular}


de flavonoides (Pridgeon et al.,1999; 2001; 2003; 2006; 2009), o que corrobora com os resultados deste trabalho, enquanto as espécies da Ásia setentrional apresentam, geralmente, abundância de alcaloides, principalmente as pertencentes aos gêneros Dendrobium (Yang et al., 2006; Roeder \& Wiedenfeld, 2009; Singh \& Duggal, 2009; Fan \& Luo, 2011) e Vanda (Kumar et al., 2000; Jalal et al., 2008; Singh \& Duggal, 2009). Ainda, tais constatações à cerca da fitoquímica em Orchidaceae, gera debates entre taxonomistas sobre o estado derivacional de representantes da família, valendo ressaltar que espécies vegetais dos neotrópicos, principalmente orquídeas, são consideradas mais diversificadas em relação aos representantes das demais áreas do globo terrestre (Pedroso-de-Moraes et al., 2006).

A detecção somente de flavonoides e taninos em Oeceoclades maculata pode estar vinculada ao fato de ter sido realizada apenas triagem fitoquímica em órgãos foliares, pois, em orquídeas terrestres asiáticas, os órgãos mais utilizados medicinalmente, e com maiores quantidades de compostos secundários, são os caulinares e principalmente os radiciais (Singh \& Duggal, 2009), possivelmente devido à sua tuberosidade. Ainda, os resultados obtidos demonstram que a temperatura usada na preparação do extrato influencia na extração de ativos fitoquímicos, levando a alterações moleculares, ou ainda, a degradação de tais substâncias. Dessa forma, a redução significativa na atividade antioxidante do extrato $E B H Q$, deve estar relacionada a esta mudança no conteúdo de polifenóis e flavonoides. Tais resultados são corroborados pelo fato de que O-heterosídeos sofrem hidrólise com o aquecimento, mesmo em soluções diluídas, podendo muitas vezes interferir na análise estrutural de flavonoides. Da mesma forma, outros componentes desta classe possivelmente são alterados pelo aquecimento (Simões, 2004).

Os flavonoides representam um dos grupos fenólicos mais importantes e diversificados entre os produtos de origem natural. Essa classe de compostos é amplamente distribuída no reino vegetal, principalmente, em angiospermas (Zuanazzi, 2001). Pode-se encontrar flavonoides em diversas formas estruturais, entretanto, a maioria deles constitui substâncias aromáticas com 15 átomos de carbono $\left(\mathrm{C}_{15}\right)$ em seu núcleo fundamental, sendo compostos fenólicos, que possuem nessa estrutura anéis aromáticos $\mathrm{C}_{6}-\mathrm{C}_{3}-\mathrm{C}_{6}$. O esqueleto $\mathrm{C}_{15}$ é biogeneticamente derivado do fenilpropano $\left(\mathrm{C}_{6}-\mathrm{C}_{3}\right)$ e três unidades de acetato $\left(\mathrm{C}_{6}\right)$. São conhecidos mais de 4.200 flavonoides, sendo que o número de novas estruturas identificadas praticamente dobrou nos últimos vinte anos (Lopes, 2000; Zuanazzi, 2001). A explicação para a existência de uma grande diversidade estrutural deste grupo químico é devida às modificações que tais compostos podem sofrer, tais como: hidroxilação, metilação, acilação e glicosilação (Lopes, 2000).

Os flavonoides de origem natural apresentam-se frequentemente oxigenados e um grande número ocorre conjugado com açúcares. Essa forma conjugada, também conhecida por glicosídeos, pode ser formada pela ligação de um ou mais açúcares aos grupos hidroxilas por ligação hemiacetal facilmente destruída por hidrólise ácida. Outra forma de conjugação de açúcares ao núcleo flavônico é por meio de ligação açúcar genina entre carbonos $C$-1 (anomérico) do açúcar e um ou dois carbonos do anel A do flavonóide (C-glicosídeo). Quando o metabólito encontra-se sem o açúcar, é chamado de aglicona ou genina (Zuanazzi, 2001) o que vale ser evidenciado, pois foi esta a forma detectada neste trabalho.

Diversas funções são atribuídas a estes fitoquímicos nas plantas. Entre elas pode-se citar: proteção dos vegetais contra incidência de radiações ionizantes, insetos, fungos, vírus e bactérias; atração de agentes polinizadores; ação antioxidante nos fotossistemas; controle da ação hormonal vegetal; ação alelopática e inibição de enzimas. Também podem ser usados como marcadores taxonômicos e isto é devido, sobretudo, a sua abundância relativa em quase todo o reino vegetal, a sua especificidade em algumas espécies, relativa estabilidade e seu acúmulo com menor influência do meio ambiente. $O$ interesse econômico desses compostos é decorrente de suas diferentes propriedades, como, por exemplo, as cores que apresentam, importância no processo de tanagem do couro, na fermentação do chá-daíndia, na manipulação do cacau e suas contribuições em nutrição e sabor dos alimentos. Além disso, esses compostos possuem também importância farmacológica, pois resultados têm apontado algumas propriedades importantes atribuídas a alguns representantes da classe, como por exemplo: anticarcinogênico, antiinflamatório, antialérgico, antiulcerogênico e antiviral (Zuanazzi, 2001).

Neste trabalho, assim como para os flavonoides, o tanino foi encontrado em grandes quantidades no extrato a frio e em pequenas no extrato quente, demonstrando termo-sensibilidade molecular. Os taninos, pertencentes aos polifenóis, quando ocorrem em grande quantidade, geralmente se localizam em órgãos específicos da planta como as folhas, os frutos e os caules (Roberts et al., 1997).

Haslam (1998) relata que as atividades farmacológicas destes metabólitos no tratamento de doenças estão diretamente relacionadas, pelo menos em parte, a três características gerais que são comuns aos taninos condensados e aos taninos hidrolisáveis: atividade antioxidante e sequestradora de radicais livres; que também 
foram observadas nesta pesquisa, indicando que os taninos podem estar envolvidos nesta atividade desta planta; complexação com íons metálicos (ferro, manganês, vanádio, cobre, alumínio e cálcio) e a habilidade de complexar com outras moléculas, incluindo macromoléculas, tais como, proteínas e polissacarídeos.

\section{CONCLUSÃO}

Maiores concentrações de flavonoides e polifenóis totais foram encontradas no extrato preparado a frio (EBHF), demonstrando que os princípios ativos encontrados nas folhas de Oeceoclades maculata são termo-sensíveis, sendo, portanto, esta forma de extração recomendada para a espécie. Considerando os resultados encontrados e a relevância da atividade antioxidante de interesse para a indústria farmacêutica, extratos de $O$. maculata merecem estudos mais aprofundados para conclusões precisas.

\section{REFERÊNCIA}

ALVES, T. M. A.; SILVA, A. F.; BRANDÃO, M.; GRANDI, T. S. M.; SMÂNIA, E. F. A.; SMÂNIA JR., A.; ZANI, C. $\mathrm{L}$. Biological screening of brazilian medicinal plants. Memórias do Instituto Oswaldo Cruz,v.95, p. 367373, 2000.

ARAÚJO, L. E.; SILVA, K. A.; FERRAZ, E. M. N.; SAMPAIO, E. V. S. B.; SILVA, S. I. Diversidade de herbáceas em microhabitats rochoso, plano e ciliar em uma área de caatinga, Caruaru, PE, Brasil. Acta Botânica Brasilica, v. 19, p. 285-294, 2005.

BATISTA, J. A. N.; BIANCHETTI, L. B. Lista atualizada das Orchidaceae do Distrito Federal. Acta Botânica Brasilica, v. 17, p. 183-201, 2003.

BATISTA, J. A. N.; BIANCHETTI, L. B.; PELLIZARO, K. F. Orchidaceae da Reserva Ecológica do Guará. Acta Botânica Brasilica, v. 19, p. 221-232, 2005.

BLOISS, S. A note on free radical formation in biologically occurring quinones.Biochimestry and Biophysics Acta, v.18, p.165, 1998.

BOSCOLO, O. H.; VALLE, L. S. Plantas de uso medicinal em Quissamã, Rio de Janeiro, Brasil. Iheringia - Série Botânica, v. 63, p. 263-277, 2008.

BULPITT, C. J.; LI, Y.; BULPITT, P. F.; WANG, J.The use of orchids in Chinese medicine.Journal of The Royal Society of Medicine, v. 100, p.558-563, 2007.

CARNIELLO, M. A.; SILVA, R. S.; CRUZ, M. A. B.; GUARIM NETO, G. Quintais urbanos de Mirassol D'Oeste-MT, Brasil: uma abordagem etnobotânica. Acta Amazonica, v. 40, p. 451-470, 2010.

COHEN, I. M.; ACKERMAN, J. D. Oeceoclades maculata, an alien tropical orchid in a Caribbean rainforest. Annals of Botany, v. 104, p. 557-563, 2009.

COSTA, A. F. Farmacognosia. Lisboa: Fundação Calouste Gulbenkian, v.3. 1986.

FAN, Y.; LUO, A. Evaluation of anti-tumor activity of water- soluble polysaccharides from Dendrobium denneanum. African Journal of Pharmacy and Pharmacology, v. 5, p. 415-420, 2011.

FERREIRA, A. L. A.; MATSUBARA, L. S. Radicais livres: conceitos, doenças relacionadas, sistema de defesa e estresse oxidativo. Revista da Associação Médica Brasileira, v. 43, p. 163-168,1997.

FERREIRA, A. W. C.; LIMA, M. I. S.; PANSARIN, E. R. Orchidaceae na região central de São Paulo, Brasil. Rodriguésia, v. 61, p. 243-259, 2010.

GASPARRI, S. Estudo das Atividades Antioxidante e Mutagênica/Antimutagênica induzidas pelo Extrato Vegetal de Costus spicatus. 2005. DissertaçãoUniversidade Luterana do Brasil, Mestrado - Diagnóstico Genético e Molecular, Canoas, 2005.

GASPI, F. O. G.; FOGLIO, M. A.; CARVALHO, J. E.; SANTOS, G. M. T.; TESTA, M.; PASSARINI JÚNIOR, J. R.; PEDROSO-DE-MORAES, C.; ESQUISATTO, M. A. M.; MENDONÇA, J. S., MENDONÇA, F. A. S. Effects of the Topical Application of Hydroalcoholic Leaf Extract of Oncidium flexuosum Sims. (Orchidaceae) and Microcurrent on the Healing of Wounds Surgically Induced in Wistar Rats. Evidence-Based Complementary and Alternative Medicine, v.20, p.1-9, 2011.

HASLAM, E. Pratical polyphenols - from structure to molecular recognition and physiological action. Cambrige: CambrigeUniversity. 1998. 67p.

IVANAUSKAS, N. M.; RODRIGUES, R. R. Florística e fitossociologia de remanescente de floresta estacional decidual em Piracicaba, São Paulo, Brasil. Revista Brasileira de Botânica, v. 23, p. 291-304, 2000.

JALAL, J. S.; KUMAR, P.; PANGTEY, Y.P.S. Ethnomedicinal Orchids of Uttarakhand, Western Himalaya. Ethnobotanical Leaflets, v. 12, p. 1227-30, 2008.

KINOSHITA, L. S.; TORRES, R. B.; FORNI-MARTINS, E. R.; SPINELLI, T.; AHN, Y. J.; CONSTÂNCIO, S. S. Composição florística e síndromes de polinização e dispersão da mata do Sítio São Francisco. Acta Botânica Brasilica, v. 20, p. 313-327, 2006.

KUMAR,P.K. S.; SUBRAMONIAM,A.;PUSHPANGANDAN, P. Aphrodisiac activity of Vanda tessellata (Roxb.) Hook.ex Don extract in male mice. Indian Journal of Pharmacology, v. 32, p. 300-304, 2000.

LOPES, R. M.; OLIVEIRA, T. T.; NAGEM, T. J.; PINTO, A. S. Flavonoides:biotecnologia ciência \& desenvolvimento. Brasitec. 2000. 326p.

MATOS, F. J. A. Introdução a fitoquímica experimental. 2 ed. Fortaleza: Edições UFC, 1997.

MENINI-NETTO, L.; ALMEIDA, V. R.; FORZZA, R.C. A família Orchidaceae em um fragmento de floresta estacional semidecidual, no município de Barroso, Minas Gerais, Brasil. Lundiana, v. 4, p. 9-24, 2004a.

MENINI-NETTO, L.; ALMEIDA, V. R.; FORZZA, R. C. A família Orchidaceae na Reserva Biológica da Represa do Grama - Descoberto, Minas Gerais, Brasil. Rodriguésia, v. 55, 137-156, 2004b.

MORI, S. A.; SILVA, L. A. M.; LISBOA, G.; CORADIN, L. Manual de manejo do herbário fanerogâmico. Ilhéus: Centro de Pesquisa do Cacau. 1989.

PANSARIN, E. R.; PANSARIN, L.M. A família Orchidaceae na Serra do Japi, São Paulo, Brasil. Rodriguésia, v. 59, p. 99-111, 2007.

PEDROSO-DE-MORAES, C.; FONTANA, C. A. D. 
Apontamentos sobre Vanilla planifolia Jacks. ex Andrews. Boletim CAOB, v.60, p.99-101, 2005.

PEDROSO-DE-MORAES, C.; POVEDANO, L.; PEDRO, N. P.; DIOGO, J. A.; FONTANA, C. A. D.; GASPI, F. O. G. Importância Fitoterápica do Gênero Vanilla (Orchidaceae). Conexão IESF, v.1, p.10-13, 2006.

PEDROSO-DE-MORAES, C.; SOUZA-LEAL, T.; PANOSSO, A. R.; CLARO, M. C. Efeitos da escarificação química e da concentração de nitrogênio sobre a germinação e o desenvolvimento in vitro de Vanilla planifolia Jack ex Andr. (Orchidaceae: Vanilloideae). Acta Botanica Brasilica, v. 23, p.714-719, 2012.

ROBERTS, J. E.; SPEEDIE, M. K.; TYLER, V. E. Farmacognosia e Farmacobiotecnologia. São Paulo: Premier. 1997. 93p.

ROEDER, E.; WIEDENFELD, R. Pyrrolizidine alkaloids in medicinal plants of Mongolia, Nepal and Tibet. Pharmazie, v. 64, p. 669-715, 2009.

SIMÕES, C. M. O.; SCHEMKEL, E. P; GOSMANN, G.; MELLO, J. C. P.; MENTZ L. A.; PETROVICK, P.R.
Farmacognosia da Planta ao Medicamento. $3^{\mathrm{a}}$ ed. Porto Alegre, Florianópolis: Ed. Universidade/ UFRGS, Ed. da UFSC, 2001. 821p.

SIMÕES, C. M. O.; SPTIZER, V. Óleos essenciais. In: SIMÕES, C. M. O. et al. Farmacognosia da Planta ao medicamento. $5^{a}$ ed. Porto Alegre/ Florianópolis: Ed. Universidade UFRGS/EdUFSCar. 2004. p. 467469.

SINGH, A.; DUGGAL, S. Medicinal Orchids - An Overview. Ethnobotanical Leaflets, v. 13, p. 399-412, 2009.

YANG, L.; QIN, L-H.; BLIGH, S. W. A.; BASHALL, A.; ZHANG, C-F.; ZHANG, M.; WANG, Z-T.; XU, L-S. A new phenanthrene with a spirolactone from Dendrobium chrysanthum and its anti-inflammatory activities. Bioorganic \& Medicinal Chemistry, v. 14, p. 34963501, 2006.

ZUANAZZI, J. S. Flavonoides. In: SIMÕES, C. M. O. et al. Farmacognosia da planta ao medicamento. 5 ed. Porto Alegre/ Florianópolis: Ed. Universidade UFRGS/ EdUFSCar, 2004. 742p. 